\title{
Different types of housing and respiratory health outcomes
}

\author{
Wen Qi Gan ${ }^{\mathrm{a}, *}$, Wayne T. Sanderson ${ }^{\mathrm{b}}$, Steven R. Browning ${ }^{\mathrm{b}}$, David M. Mannino ${ }^{\mathrm{a}}$ \\ a Department of Preventive Medicine and Environmental Health, University of Kentucky College of Public Health, Lexington, KY, USA \\ b Department of Epidemiology, University of Kentucky College of Public Health, Lexington, KY, USA
}

\section{A R T I C L E I N F O}

\section{Article history:}

Received 26 October 2016

Received in revised form 22 March 2017

Accepted 28 May 2017

Available online 8 June 2017

\section{Keywords:}

Environmental exposure

Epidemiology

Housing

Respiratory disease

\begin{abstract}
A B S T R A C T
Evidence has shown that housing conditions may substantially influence the health of residents. Different types of housing have different structures and construction materials, which may affect indoor environment and housing conditions. This study aimed to investigate whether people living in different types of housing have different respiratory health outcomes. The data from the 1999-2006 National Health and Nutrition Examination Survey were used for the analyses. The types of housing included houses, townhouses, apartments, and mobile homes. Respiratory symptoms included wheezing, coughing, sputum, and dyspnea; respiratory diseases included asthma, chronic bronchitis, emphysema, and chronic obstructive pulmonary disease (COPD). Multiple logistic regression was used to calculate odds ratio (OR) and 95\% confidence interval $(\mathrm{CI})$ after adjustment for potential confounding factors. A total of 11,785 participants aged 40 years and older were included in the analyses. Compared with those living in single family houses, participants living in mobile homes were more likely to have respiratory conditions, the OR (95\% CI) was $1.38(1.13-1.69)$ for wheezing, and 1.49 (1.25-1.78) for dyspnea; whereas participants living in apartments were less likely to have respiratory conditions, the OR $(95 \% \mathrm{CI})$ was $0.58(0.36-0.91)$ for chronic bronchitis, and 0.69 (0.490.97 ) for COPD. Compared with living in single family houses, living in mobile home was associated with worse, whereas living in apartments was associated with better, respiratory health outcomes. Further research is needed to better understand the underlying mechanisms and prevent adverse respiratory effects associated with living in mobile homes.
\end{abstract}

(c) 2017 The Authors. Published by Elsevier Inc. This is an open access article under the CC BY-NC-ND license (http://creativecommons.org/licenses/by-nc-nd/4.0/).

\section{Introduction}

There is growing recognition that the built environment may profoundly influence the physical and mental health of inhabitants (Perdue et al., 2003; Sallis et al., 2012; Srinivasan et al., 2003). Built environment encompasses all buildings and spaces created or modified by humans (Srinivasan et al., 2003), but family housing may be particularly important because people spend the majority of their time at home (Hancock, 2002; Klepeis et al., 2001). In recent two decades, accumulating evidence has shown that housing quality and conditions may affect the health of residents (Hood, 2005; Jacobs, 2011; Krieger and Higgins, 2002; Matte and Jacobs, 2000). For example, substandard housing may increase exposures to biological (e.g., molds, mites, roaches), chemical (e.g., lead, carbon monoxide, volatile organic compounds), and physical (e.g., extreme temperature, fine particles, radon) hazards (Bonnefoy, 2007; Jacobs, 2011), leading to a wide range of adverse health outcomes, especially respiratory diseases (Bonnefoy, 2007; Hood, 2005;

\footnotetext{
* Corresponding author at: 111 Washington Avenue, Lexington, KY 40536, USA

E-mail address: wenqi.gan@uky.edu (W.Q. Gan).
}

Jacobs, 2011; Krieger and Higgins, 2002; Matte and Jacobs, 2000). Whereas housing interventions to improve housing conditions such as elimination of moisture intrusion, integrated pest management, and active radon mitigation can effectively reduce respiratory conditions (Krieger et al., 2010; Sandel et al., 2010). These studies provide convincing evidence that housing is related to health through housing quality and conditions.

According to the 2011 American Housing Survey (US Census Bureau, 2013), there are approximately 132 million homes in the US, about 63\% are detached single-family homes, 30\% are attached family homes including duplexes and apartments, and $7 \%$ are manufactured homes or trailers (mobile homes). Different types of housing have different structures and construction materials, which may substantially affect housing conditions and indoor environment. People living in different types of housing may thus be exposed to different levels of indoor pollutants, leading to different health outcomes. Based on the hypothesis, we conducted this study to investigate whether people living in different types of housing have different respiratory health outcomes, using a nationally representative sample of US adults from the 1999-2006 National Health and Nutrition Examination Survey (NHANES). 


\section{Methods}

\subsection{Study population}

The NHANES is a series of cross-sectional surveys conducted by the US National Center for Health Statistics. During each survey, a nationally representative sample of the civilian noninstitutionalized population is selected using a complex multistage sampling design to estimate the health and nutritional status of the US population (Johnson et al., 2013; Zipf et al., 2013). The survey consists of a household interview and a medical examination. In the household interview, various health-related questionnaires such as medical conditions are administered by a trained interviewer. Detailed information on the study population and the survey design is available elsewhere (Johnson et al., 2013; Zipf et al., 2013).

There are four two-year cycles of NHANES (1999-2000, 20012002, 2003-2004, and 2005-2006) that comprise information on types of housing in the questionnaire of housing characteristics. We aggregated these data to create a combined dataset (NHANES 1999-2006). Because chronic respiratory diseases such as emphysema and chronic bronchitis are relatively rare among people $<40$ years old, the self-reported diagnoses of these diseases may not be accurate among these participants. Further, young people are generally more likely to change residences, their current residences might not be related to their respiratory conditions. Additionally, in NHANES, some respiratory symptoms data such as dyspnea were collected only for people aged 40 years and older. Therefore, this study was restricted to participants aged 40 years and older who participated in the medical examination. For these participants, the overall response rate during NHANES 1999-2006 was 68\% (Centers for Disease Control and Prevention, n.d.). The NHANES 1999-2006 was reviewed and approved by the NCHS Institutional Review Board; informed consent was obtained from all participants.

\subsection{Types of housing}

According to the questionnaire of housing characteristics during NHANES 1999-2006, the types of housing for participants' current homes at the time of interview were defined as follows:

House: A one family house detached from any other house.

Apartment: An apartment.

Townhouse: A one family house attached to one or more houses.

Mobile home: A mobile home or trailer.

2.3. Respiratory health outcomes

2.3.1. Respiratory symptoms: the presence of a respiratory symptom was defined by answering 'yes' to the corresponding question

Wheezing: 'In the past 12 months, have you had wheezing or whistling in your chest?'.

Coughing: 'Do you usually cough on most days for 3 consecutive months or more during the year?'.

Sputum: 'Do you bring up phlegm on most days for 3 consecutive months or more during the year?'.

Dyspnea: 'Have you had shortness of breath either when hurrying on the level or walking up a slight hill?'. The question was regarding a person's current general situation at the time of interview.

2.3.2. Respiratory diseases: respiratory diseases were defined as self-reported diagnosis by a doctor or other health professionals, unless otherwise specified

Asthma: was defined by answering 'yes' to the following two questions: (1) 'Has a doctor or other health professional ever told you that you have asthma?'; (2) 'Do you still have asthma?'.
Chronic bronchitis: was defined by answering 'yes' to the following two questions: (1) 'Has a doctor or other health professional ever told you that you have chronic bronchitis?'; (2) 'Do you still have chronic bronchitis?'.

Emphysema: was defined by answering 'yes' to the question 'Has a doctor or other health professional ever told you that you had emphysema?'.

Chronic obstructive pulmonary disease (COPD): was defined by having chronic bronchitis, emphysema, or both.

2.4. Potential confounding factors

Based on the questionnaire design and the frequency distribution, potential confounding factors were categorized as follows:

Age (Bousquet and Khaltaev, 2007; Global Initiative for Chronic Obstructive Lung Disease, 2017): the participants were divided into quartiles based on their age: $40-49,50-61,62-72$, or $73-$ 85 years.

Sex (Global Initiative for Chronic Obstructive Lung Disease, 2017; Han et al., 2007): men, women.

Race/ethnicity (Bousquet and Khaltaev, 2007; Global Initiative for Chronic Obstructive Lung Disease, 2017): non-Hispanic white, non-Hispanic black, Mexican American, or other.

Body mass index (BMI) (Bousquet and Khaltaev, 2007; Global Initiative for Chronic Obstructive Lung Disease, 2017): BMI was calculated by a person's weight in kilograms divided by the square of height in meters. Based on BMI, the participants were divided into four groups: $<18.5 \mathrm{~kg} / \mathrm{m}^{2}$ (underweight), $18.5-24 \mathrm{~kg} / \mathrm{m}^{2}$ (normal), $25-29 \mathrm{~kg} / \mathrm{m}^{2}$ (overweight), $\geq 30 \mathrm{~kg} / \mathrm{m}^{2}$ (obese). Also, an "unknown" group was included to retain those with missing data on BMI.

Educational attainment (Bousquet and Khaltaev, 2007; Global Initiative for Chronic Obstructive Lung Disease, 2017): less than high school, high school (including general equivalency diploma), and more than high school.

Family income-to-poverty ratio (Bousquet and Khaltaev, 2007; Global Initiative for Chronic Obstructive Lung Disease, 2017): the ratio of annual household income to the family's corresponding poverty threshold published by the US Census Bureau in a given calendar year (US Census Bureau, n.d.). The ratio takes into account annual family income, family size, and the minimum income needed to support the family in a specific year. The participants were divided into tertiles based on their income-to-poverty ratios, representing low ( $\leq 1.56)$, medium (1.57-3.57), and high ( $\geq 3.58)$ family income levels, respectively. Also, an "unknown" group was included to retain the participants with missing data on family income-to-poverty ratio.

Leisure time physical activity (Bousquet and Khaltaev, 2007): on the basis of self-reported frequency and duration of participation in various moderate and vigorous physical activities during the past 30 days, the weekly total number of minutes spent in moderate (weekly frequency multiplied by the average duration of activity) and vigorous (weekly frequency multiplied by the average duration of activity multiplied by 2) physical activity was calculated for each participant. Ideal, intermediate and poor levels of physical activity were defined as $\geq 150,1-149$, and 0 min of physical activity each week, respectively (Caleyachetty et al., 2015; Ford et al., 2012).

Cigarette smoking status (Bousquet and Khaltaev, 2007; Global Initiative for Chronic Obstructive Lung Disease, 2017): current smokers (had smoked $\geq 100$ cigarettes in lifetime and still smoked at the time of interview), former smokers (had smoked $\geq 100$ 
cigarettes in lifetime but did not smoke at the time of interview), and never smokers (had not smoked $\geq 100$ cigarettes in lifetime).

Secondhand smoke (Bousquet and Khaltaev, 2007; Global Initiative for Chronic Obstructive Lung Disease, 2017): was defined by answering 'yes' to any of the two question: (1) 'Does anyone who lives here smoke cigarettes, cigars, or pipes anywhere inside this home?'; (2) for currently employed workers, 'At this job or business, can you smell the smoke from other people's cigarettes, cigars, and/ or pipes?'.

Year of construction for the current home: mobile home is not common before 1978, the numbers of participants living in mobile homes are very small. Therefore the year a home was built was divided into two groups: before 1977, or 1978 and later. An "unknown" group was included to retain the participants with missing data on year of construction.

Home ownership (Bousquet and Khaltaev, 2007; Global Initiative for Chronic Obstructive Lung Disease, 2017): owned, or nonowned including rented or other.

\subsection{Statistical analysis}

The characteristics of the participants were compared by types of housing using the Rao-Scott $\chi^{2}$ test for categorical variables. To assess the reliability of each estimated proportion, relative standard error (RSE) was calculated by dividing the SE of the estimate by the estimate itself, multiplying that result by 100 . An estimate with RSE above $30 \%$ was considered statistically unreliable (Johnson et al., 2013). Multiple logistic regression was used to calculate odds ratios (OR) and 95\% confidence intervals $(\mathrm{CI})$ of each respiratory outcome for participants living in townhouses, apartments, and mobile homes, respectively, by using those living in single family houses as the reference group. The analyses were adjusted for age, sex, race/ethnicity, BMI, education attainment, family income-to-poverty ratio, leisure time physical activity, cigarette smoking, secondhand smoke, year of construction of the home, and home ownership.

The NHANES 1999-2006 used a complex multistage sampling design, therefore the sample weights for the combined 8-year data were constructed using the medical exam weights (Gan et al., 2016; Johnson et al., 2013). The sample weights were incorporated into all analyses to account for the complex sampling design, differential probabilities of selection, non-coverage, and non-response of the survey (Johnson et al., 2013). The SAS Survey Procedure (SAS 9.4, SAS Institute Inc., Cary, NC, USA) was used to perform the statistical analysis. All statistical tests were 2 -sided, $P<0.05$ was regarded as statistically significant.

\section{Results}

A total of 11,844 participants aged 40 years and older had complete data on types of housing for the NHANES 1999-2006. After excluding 59 persons with missing data on education attainment, cigarette smoking, secondhand smoke, or home ownership, leaving 11,785 participants for the current analyses. For these participants, average age was 57 years (range $40-85$ years), 53.1\% were women. 73.6\% lived in houses, 6.9\% in townhouse, $12.3 \%$ in apartments, and $7.2 \%$ in mobile homes (weighted percentages).

Compared with those living in single family houses, participants living in apartments and mobile homes had lower SES status, indicated by lower education attainment and lower income-to-poverty ratio; they were more likely to have poor leisure time physical activity, be current smokers, and be exposed to secondhand smoke; their homes were less likely to be built before 1977, especially for mobile homes. Participants living in houses and mobile homes were more likely to be Non-Hispanic white; they were more likely to own the homes, especially for those living in houses (Table 1).
Table 1

Characteristics of participants by different types of housing. ${ }^{\text {a }}$

\begin{tabular}{|c|c|c|c|c|}
\hline & $\begin{array}{l}\text { House } \\
(\mathrm{n}=8128)\end{array}$ & $\begin{array}{l}\text { Townhouse } \\
(n=907)\end{array}$ & $\begin{array}{l}\text { Apartment } \\
(\mathrm{n}=1867)\end{array}$ & $\begin{array}{l}\text { Mobile home } \\
(\mathrm{n}=883)\end{array}$ \\
\hline \multicolumn{5}{|l|}{ Age (quartiles), yr } \\
\hline$\leq 49$ & $1870(32.3)$ & $216(29.1)$ & $547(35.3)$ & $226(31.7)$ \\
\hline $50-61$ & $2128(33.9)$ & $221(30.1)$ & $428(28.4)$ & $211(29.7)$ \\
\hline $62-72$ & $2128(18.8)$ & $217(20.8)$ & $380(14.6)$ & $219(20.0)$ \\
\hline$\geq 73$ & $2002(15.0)$ & $253(20.0)$ & $512(21.7)$ & 227 (18.5) \\
\hline \multicolumn{5}{|l|}{ Sex } \\
\hline Men & 4106 (47.9) & $409(43.2)$ & $890(42.7)$ & $453(46.8)$ \\
\hline Women & $4022(52.1)$ & $498(56.8)$ & $977(57.3)$ & $430(53.2)$ \\
\hline \multicolumn{5}{|l|}{ Race/Ethnicity } \\
\hline Non-Hispanic white & $4652(80.6)$ & 453 (70.9) & $690(54.8)$ & $542(81.3)$ \\
\hline Non-Hispanic black & $1353(7.8)$ & $288(17.4)$ & $584(20.8)$ & $100(6.5)$ \\
\hline Mexican-American & $1718(4.7)$ & $103(3.3)$ & $331(6.0)$ & $201(6.1)$ \\
\hline Other & $405(6.9)$ & $63(8.5)$ & $262(18.4)$ & $40(6.1)$ \\
\hline \multicolumn{5}{|l|}{ BMI (quartiles), $\mathrm{kg} / \mathrm{m}^{2}$} \\
\hline$<18.5$ (underweight) & $87(1.2)$ & $11(1.2)$ & $33(1.9)$ & $11(1.1)$ \\
\hline $18.5-24.9$ (normal) & $2067(27.2)$ & $254(31.3)$ & $519(29.4)$ & $188(20.6)$ \\
\hline 25.0-29.9 (overweight) & $2990(35.8)$ & $332(35.4)$ & $621(32.4)$ & $311(32.4)$ \\
\hline$\geq 30$ (obese) & $2717(33.4)$ & $284(30.1)$ & $604(31.6)$ & $326(41.6)$ \\
\hline Unknown & $267(2.4)$ & $26(2.0)$ & $90(4.7)$ & $47(4.3)$ \\
\hline \multicolumn{5}{|l|}{ Education } \\
\hline$<$ High school & $2547(17.6)$ & $285(20.3)$ & $823(32.8)$ & $404(33.1)$ \\
\hline High school & $1883(25.6)$ & $213(24.6)$ & $422(25.1)$ & $232(33.5)$ \\
\hline$>$ High school & $3698(56.8)$ & $409(55.1)$ & $622(42.0)$ & $247(33.3)$ \\
\hline \multicolumn{5}{|c|}{ Family income-to-poverty ratio (tertiles) } \\
\hline Low $(\leq 1.56)$ & $1995(15.3)$ & $263(21.1)$ & $928(43.9)$ & 445 (39.9) \\
\hline Medium (1.57-3.57) & $2591(29.7)$ & $271(28.1)$ & $509(28.6)$ & $273(34.7)$ \\
\hline High $(\geq 3.58)$ & $2929(48.8)$ & $314(44.7)$ & $276(20.5)$ & $123(20.5)$ \\
\hline Unknown & $613(6.2)$ & $59(6.1)$ & $154(7.0)$ & $42(4.9)$ \\
\hline \multicolumn{5}{|c|}{ Leisure time physical activity } \\
\hline Poor & $3718(37.0)$ & $444(40.6)$ & $1061(52.2)$ & $545(57.3)$ \\
\hline Intermediate & $1707(23.5)$ & $186(24.3)$ & $350(20.2)$ & $158(18.6)$ \\
\hline Ideal & $2703(39.5)$ & $277(35.1)$ & $456(27.6)$ & $180(24.0)$ \\
\hline \multicolumn{5}{|l|}{ Cigarette smoking } \\
\hline Current smoker & $1340(17.7)$ & $201(23.6)$ & $481(28.8)$ & 259 (33.9) \\
\hline Former smoker & $2823(33.5)$ & 307 (33.5) & $518(24.8)$ & $313(33.0)$ \\
\hline Never smoker & 3965 (48.9) & 399 (43.0) & $868(46.5)$ & $311(33.1)$ \\
\hline \multicolumn{5}{|l|}{ Secondhand smoke } \\
\hline Yes & $1832(24.5)$ & $260(29.7)$ & $542(33.0)$ & $327(43.2)$ \\
\hline No & $6296(75.5)$ & 647 (70.3) & $1325(67.0)$ & $556(56.8)$ \\
\hline \multicolumn{5}{|l|}{ Year of construction } \\
\hline Before 1977 & $5024(58.5)$ & $453(48.6)$ & $659(36.8)$ & $226(22.2)$ \\
\hline 1978 and later & $2275(36.3)$ & $279(37.0)$ & $411(27.2)$ & $544(68.8)$ \\
\hline Unknown & $829(5.3)$ & $175(14.4)$ & $797(36.1)$ & $113(9.0)$ \\
\hline \multicolumn{5}{|l|}{ Home ownership } \\
\hline Owned & 7294 (91.7) & $582(65.6)$ & $204(12.4)$ & 739 (84.4) \\
\hline Non-owned & $834(8.3)$ & $325(34.4)$ & $1663(87.6)$ & $144(15.6)$ \\
\hline
\end{tabular}

a Data are presented as unweighted sample size (weighted prevalence). All relative SES for estimated percentages are $<30 \% . P<0.001$ for all comparisons between the four groups.

Table 2 shows that the weighted prevalence of respiratory symptoms and diseases was similar for participants living in houses and townhouses, but was lower compared with the prevalence for those living in apartments and mobile homes. Participants living in mobile homes had substantially elevated prevalence in all these respiratory symptoms and diseases compared with those living in other types of housing.

Table 3 presents the results of the multiple logistic regression analyses for the associations between different types of housing and respiratory conditions after adjustment for potential confounders. Compared with those living in single family houses, participants living in mobile homes were more likely to have respiratory symptoms and diseases (except for emphysema); the difference was statistically significant for wheezing (OR, 1.38; 95\% CI, 1.13-1.69), and dyspnea (OR, 1.49; 95\% 
Table 2

Weighted prevalence (SE) of respiratory symptoms and diseases for participants living in different types of housing.

\begin{tabular}{lllll}
\hline & $\begin{array}{l}\text { House } \\
(\mathrm{n}=8128)\end{array}$ & $\begin{array}{l}\text { Townhouse } \\
(\mathrm{n}=907)\end{array}$ & $\begin{array}{l}\text { Apartment } \\
(\mathrm{n}=1867)\end{array}$ & $\begin{array}{l}\text { Mobile home } \\
(\mathrm{n}=883)\end{array}$ \\
\hline $\begin{array}{l}\text { Respiratory symptom } \\
\text { Wheezing }\end{array}$ & $14.9(0.6)$ & $15.0(1.7)$ & $17.1(1.1)$ & $25.7(1.6)$ \\
Coughing & $10.8(0.6)$ & $10.4(1.3)$ & $11.9(1.1)$ & $17.8(2.0)$ \\
Sputum & $9.9(0.5)$ & $8.1(1.3)$ & $11.9(1.1)$ & $16.6(1.7)$ \\
Dyspnea & $34.2(1.0)$ & $34.4(2.4)$ & $40.0(1.7)$ & $51.8(2.1)$ \\
Respiratory disease & & & & \\
Asthma & $7.5(0.5)$ & $8.1(1.6)$ & $8.3(1.0)$ & $9.8(1.3)$ \\
Chronic bronchitis & $3.5(0.2)$ & $3.5(0.8)$ & $3.4(0.6)$ & $6.4(1.2)$ \\
Emphysema & $2.5(0.2)$ & $2.6(0.6)$ & $3.4(0.6)$ & $3.9(0.9)$ \\
COPD & $5.4(0.3)$ & $5.3(0.9)$ & $6.1(0.8)$ & $9.1(1.4)$ \\
\hline
\end{tabular}

CI, 1.25-1.78). Compared with those living in single family houses, participants living in apartments and townhouses had better respiratory health profiles; overall, they were less likely to have respiratory symptoms and diseases. For participants living in apartments, the difference was statistically significant for chronic bronchitis (OR, 0.58; $95 \% \mathrm{CI}$, 0.36-0.91), and COPD (OR, 0.69; 95\% CI, 0.49-0.97) (Table 3).

\section{Discussion}

On the basis of a large nationally representative sample of US adults aged 40 years and older, we found that compared with those living in single family houses, in general, participants living in mobile homes were more likely, whereas participants living in apartments were less likely, to have respiratory symptoms and diseases. Although most of the differences were not statistically significant, the overall trends were evident. Given that housing is the essential human requirements, the findings may have important implications for public health.

Socioeconomic factors may play a key role in selecting types of housing and determining housing conditions (Adamkiewicz et al., 2014; Haines et al., 2013; Hood, 2005; Jacobs, 2011). Meanwhile, SES is a known risk factor for respiratory conditions (Prescott and Vestbo, 1999; Ramsay et al., 2011). Therefore SES was a major confounding factor for the association between different types of housing and respiratory conditions. To address this concern, we included three socioeconomic factors (income-to-poverty ratio, education attainment, and home ownership) in the statistical analyses, the influences of SES on the observed associations should be reasonably diminished. In addition, as discussed before (Table 1), participants living in mobile homes and apartments had comparable SES in terms of income-to-poverty ratio and education attainment. However, the vast majority of participants living in mobile homes (84\%), in contrast to a small proportion of participants living in apartments (12\%), owned their homes, indicating that participants living in mobile homes might have better SES compared with those living in apartments. Therefore, the observed differences in respiratory outcomes between people living in mobile homes and apartments were less likely to result from socioeconomic confounding.

Although the exact mechanisms underlying the observed associations were not clear, the following reasons might partly explain the observed differences in respiratory health outcomes between people living in houses, apartments, and mobile homes. First, apartments might be managed by specialized staff, and thus were more likely to be well maintained compared with houses or mobile homes, where there was generally no such management service. Further, approximately $88 \%$ of participants living in apartments rented their homes (in contrast to $8 \%$ house dwellers, $16 \%$ mobile home dwellers), these homes might be maintained by specialized staff for normal functions and conditions. As the presence of the specialized maintenance services, it is presumed that these homes were less likely to be exposed to severe indoor pollutants. Second, multifamily apartment buildings generally have mechanical ventilation to maintain adequate fresh air supply, but single family homes typically rely on passive air infiltration for air exchange, and mobile homes have a much lower air exchange rate and thus less fresh air supply (Francisco et al., 2017). The differences in ventilation condition and fresh air supply may play a role in the associations between different types of housing and respiratory conditions (Jacobs et al., 2010; Sundell et al., 2011; WHO European Centre for Environment and Health, 2005). Third, there is evidence that residents with greater access to healthy foods tend to have healthier diets and lower levels of obesity (Bodor et al., 2008; Larson et al., 2009; Morland et al., 2002; Rose and Richards, 2004). Multifamily apartment buildings are generally closer to local resources such as shopping centers, residents of these homes might have greater accessibility to healthy foods such as fresh fruits and vegetables, which might provide some protection from chronic respiratory conditions. Finally, compared with single family homes or mobile homes, multifamily apartment buildings, especially high-rise buildings, may have better quality (e.g., concrete vs. wood or particleboard) and conditions (e.g., insulation, sanitation, air-conditioning), and were less likely to have severe indoor pollutants (e.g., moisture, molds, mites, radon). Meanwhile, mobiles homes are built mainly using engineered wood products such as particleboard, plywood, and fiberboard (Frumkin, 2016). These materials might release volatile organic compounds such as formaldehyde. A study of 519 temporary mobile homes found that the geometric mean of formaldehyde levels was $77 \mathrm{ppb}$ (range 3-590 ppb), 2-3 times the typical indoor formaldehyde level in US homes (Centers for Disease Control and Prevention, 2008). Formaldehyde is a colorless gas with a pungent and irritating odor at room temperature, chronic inhalation of formaldehyde might contribute to the development of respiratory conditions (Mathur and Rastogi, 2007; McGwin et al., 2010).

This study has some limitations that should be considered. First, this is a cross-sectional study, in which living in different types of housing and respiratory conditions were existent simultaneously, the temporal

Table 3

ORs (95\% CIs) of respiratory symptoms and diseases for participants living in different types of housing. ${ }^{\mathrm{a}}$

\begin{tabular}{|c|c|c|c|c|}
\hline & $\begin{array}{l}\text { House } \\
(\mathrm{n}=8128)\end{array}$ & $\begin{array}{l}\text { Townhouse } \\
(\mathrm{n}=907)\end{array}$ & $\begin{array}{l}\text { Apartment } \\
(\mathrm{n}=1867)\end{array}$ & $\begin{array}{l}\text { Mobile home } \\
(\mathrm{n}=883)\end{array}$ \\
\hline \multicolumn{5}{|c|}{ Respiratory symptoms } \\
\hline Wheezing & 1.00 (referent) & $0.88(0.64-1.21)$ & $0.80(0.63-1.02)$ & $1.38(1.13-1.69)$ \\
\hline Coughing & 1.00 (referent) & $0.85(0.64-1.14)$ & $0.86(0.65-1.14)$ & $1.12(0.85-1.48)$ \\
\hline Sputum & 1.00 (referent) & $0.71(0.50-0.99)$ & $1.03(0.79-1.33)$ & $1.25(0.96-1.63)$ \\
\hline Dyspnea & 1.00 (referent) & $0.88(0.70-1.11)$ & $0.93(0.76-1.15)$ & $1.49(1.25-1.78)$ \\
\hline \multicolumn{5}{|l|}{ Respiratory diseases } \\
\hline Asthma & 1.00 (referent) & $1.01(0.62-1.64)$ & $0.90(0.66-1.24)$ & $1.20(0.81-1.76)$ \\
\hline Chronic bronchitis & 1.00 (referent) & $0.78(0.49-1.24)$ & $0.58(0.36-0.91)$ & $1.47(0.93-2.33)$ \\
\hline Emphysema & 1.00 (referent) & $0.78(0.45-1.36)$ & $0.80(0.51-1.25)$ & $0.88(0.51-1.52)$ \\
\hline COPD & 1.00 (referent) & $0.76(0.53-1.10)$ & $0.69(0.49-0.97)$ & $1.21(0.80-1.84)$ \\
\hline
\end{tabular}

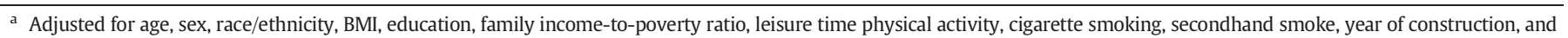
home ownership. 
relation between types of housing and respiratory conditions was not certain. Meanwhile, it was possible that some participants might have changed their housing types at the time of interview because of respiratory conditions, leading to misclassification of housing types, which would potentially bias the effect estimates toward the null. Second, there were no clear definitions on different types of housing in the questionnaire of housing characteristics. When answering the question on "type of home", participants chose an answer based on their own understanding. In practice, sometimes the differences between an apartment and a townhouse as well as a house and a mobile home were not clear, misclassification of housing types was thus possible, which would potentially bias the effect estimates toward the null. Third, in the current study, respiratory symptoms were defined by self-reports, respiratory diseases were defined as self-reported diagnoses by doctors or other health professionals. Because of incorrect recall or lack of medical knowledge, the information on self-reported respiratory symptoms and diseases might be not accurate. Fourth, some evidence shows that living with pets is associated with respiratory conditions (Plaschke et al., 1999; Svanes et al., 2003). Information on living with pets was not collected during the NHANES 1999-2006, and thus the influence of living with pets could not be controlled in the analyses. Finally, there was no on-site measurement for indoor pollutants that might potentially underlie the observed associations, it was thus not likely to compare the levels of potential pollutants between different types of housing. Future studies are needed to confirm our preliminary findings, and to better understand potential mechanisms underlying the observed differences in respiratory conditions associated with living in different types of housing.

\section{Conclusions}

Adequate housing is the basic human requirement, how to improve housing conditions and prevent housing-related health problems is an important public health issue. On the basis of a large nationally representative sample of US adults, we found that compared with living in single family houses, living in mobile home was associated with worse, whereas living in apartments was associated with better, respiratory health outcomes. Although the exact mechanisms underlying the observed differences were not clear, the findings may have important implications for public health. In the US, approximately 18 million people live in mobile homes (Centers for Disease Control and Prevention and U.S. Department of Housing and Urban Development, 2011). Although mobile homes are more affordable than traditional houses, the adverse respiratory effects are notable. Addressing adverse respiratory effects related to mobile homes may represent a great opportunity to better prevent and control housing-related health problems. The standards and practices found in multi-family apartment buildings should be considered to be extended to single family homes and mobile homes.

\section{Funding}

This research did not receive any specific grant from funding agencies in the public, commercial, or not-for-profit sectors.

\section{Conflict of interest}

The authors declare there is no conflict of interest.

\section{References}

Adamkiewicz, G., Spengler, J.D., Harley, A.E., et al., 2014. Environmental conditions in lowincome urban housing: clustering and associations with self-reported health. Am. J. Public Health 104, 1650-1656.

Bodor, J.N., Rose, D., Farley, T.A., et al., 2008. Neighbourhood fruit and vegetable availability and consumption: the role of small food stores in an urban environment. Public Health Nutr. 11, 413-420.
Bonnefoy, X., 2007. Inadequate housing and health: an overview. Int. J. Environ. Pollut. 30, 411-429.

Bousquet, J., Khaltaev, N., 2007. Global Surveillance, Prevention and Control of Chronic Respiratory Diseases: A Comprehensive Approach. World Health Organization, Geneva http://www.who.int/iris/handle/10665/43776 (Access on: March 15, 2017).

Caleyachetty, R., Echouffo-Tcheugui, J.B., Muennig, P., et al., 2015. Association between cumulative social risk and ideal cardiovascular health in US adults: NHANES 19992006. Int. J. Cardiol. 191, 296-300.

Centers for Disease Control and Prevention, 2008. Final report on formaldehyde levels in FEMA-supplied travel trailers, park models, and mobile homes. https://www.cdc.gov/ nceh/ehhe/trailerstudy/pdfs/femafinalreport.pdf (Access on: March 15, 2017).

Centers for Disease Control and Prevention, (n.d.) NHANES response rates and population totals. http://www.cdc.gov/nchs/nhanes/response_rates_cps.htm (Access on: March 15, 2017).

Centers for Disease Control and Prevention, U.S. Department of Housing and Urban Development, 2011. Safety and health in manufactured structures. http://www.cdc. gov/healthyhomes/manufactured_structures.pdf (Access on: March 15, 2017).

Ford, E.S., Greenlund, K.J., Hong, Y., 2012. Ideal cardiovascular health and mortality from all causes and diseases of the circulatory system among adults in the United States. Circulation 125, 987-995.

Francisco, P.W., Jacobs, D.E., Targos, L., et al., 2017. Ventilation, indoor air quality, and health in homes undergoing weatherization. Indoor Air 27, 463-477.

Frumkin, H., 2016. Building and health. In: Frumkin, H. (Ed.), Environmental Health: From Global to Local. John Wiley \& Sons, Inc., San Francisco, CA, pp. 539-579.

Gan, W.Q., Moline, J., Kim, H., et al., 2016. Exposure to loud noise, bilateral high-frequency hearing loss and coronary heart disease. Occup. Environ. Med. 73, 34-41.

Global Initiative for Chronic Obstructive Lung Disease, 2017. Global strategy for the diagnosis, management and prevention of chronic obstructive pulmonary disease (2017 report). file://C:/Users/wga228/Downloads/wms-GOLD-2017-FINAL.pdf (Access on: March 15, 2017)

Haines, A., Bruce, N., Cairncross, S., et al., 2013. Promoting health and advancing development through improved housing in low-income settings. J. Urban Health 90 810-831.

Han, M.K., Postma, D., Mannino, D.M., et al., 2007. Gender and chronic obstructive pulmonary disease: why it matters. Am. J. Respir. Crit. Care Med. 176, 1179-1184.

Hancock, T., 2002. Indicators of environmental health in the urban setting. Can. J. Public Health 93 (Suppl. 1), S45-S51.

Hood, E., 2005. Dwelling disparities: how poor housing leads to poor health. Environ. Health Perspect. 113, A310-A317.

Jacobs, D.E., 2011. Environmental health disparities in housing. Am. J. Public Health 101 (Suppl. 1), S115-S122.

Jacobs, D.E., Brown, M.J., Baeder, A., et al., 2010. A systematic review of housing interventions and health: introduction, methods, and summary findings. J. Public Health Manag. Pract. 16, S5-S10.

Johnson, C.L., Paulose-Ram, R., Ogden, C.L., et al., 2013. National health and nutrition examination survey: analytic guidelines, 1999-2010. Vital Health Stat. 2, 1-24.

Klepeis, N.E., Nelson, W.C., Ott, W.R., et al., 2001. The National Human Activity Pattern Survey (NHAPS): a resource for assessing exposure to environmental pollutants. J. Expo. Anal. Environ. Epidemiol. 11, 231-252.

Krieger, J., Higgins, D.L., 2002. Housing and health: time again for public health action. Am. J. Public Health 92, 758-768.

Krieger, J., Jacobs, D.E., Ashley, P.J., et al., 2010. Housing interventions and control of asthma-related indoor biologic agents: a review of the evidence. J. Public Health Manag. Pract. 16, S11-S20.

Larson, N.I., Story, M.T., Nelson, M.C., 2009. Neighborhood environments: disparities in access to healthy foods in the U.S. Am. J. Prev. Med. 36, 74-81.

Mathur, N., Rastogi, S.K., 2007. Respiratory effects due to occupational exposure to formaldehyde: systematic review with meta-analysis. Indian J. Occup. Environ. Med. 11, 26-31.

Matte, T.D., Jacobs, D.E., 2000. Housing and health-current issues and implications for research and programs. J. Urban Health 77, 7-25.

McGwin, G., Lienert, J., Kennedy, J.I., 2010. Formaldehyde exposure and asthma in children: a systematic review. Environ. Health Perspect. 118, 313-317.

Morland, K., Wing, S., Diez Roux, A., 2002. The contextual effect of the local food environment on residents' diets: the atherosclerosis risk in communities study. Am. J. Public Health 92, 1761-1767.

Perdue, W.C., Stone, L.A., Gostin, L.O., 2003. The built environment and its relationship to the public's health: the legal framework. Am. J. Public Health 93, 1390-1394.

Plaschke, P., Janson, C., Norrman, E., et al., 1999. Association between atopic sensitization and asthma and bronchial hyperresponsiveness in Swedish adults: pets, and not mites, are the most important allergens. J. Allergy Clin. Immunol. 104, 58-65.

Prescott, E., Vestbo, J., 1999. Socioeconomic status and chronic obstructive pulmonary disease. Thorax 54, 737-741.

Ramsay, S.E., Whincup, P.H., Lennon, L.T., et al., 2011. Longitudinal associations of socioeconomic position in childhood and adulthood with decline in lung function over 20 years: results from a population-based cohort of British men. Thorax 66 1058-1064.

Rose, D., Richards, R., 2004. Food store access and household fruit and vegetable use among participants in the US Food Stamp Program. Public Health Nutr. 7, 1081-1088.

Sallis, J.F., Floyd, M.F., Rodriguez, D.A., et al., 2012. Role of built environments in physical activity, obesity, and cardiovascular disease. Circulation 125 729-737.

Sandel, M., Baeder, A., Bradman, A., et al., 2010. Housing interventions and control of health-related chemical agents: a review of the evidence. J. Public Health Manag. Pract. 16, S24-S33. 
Srinivasan, S., O'Fallon, L.R., Dearry, A., 2003. Creating healthy communities, healthy homes, healthy people: initiating a research agenda on the built environment and public health. Am. J. Public Health 93, 1446-1450.

Sundell, J., Levin, H., Nazaroff, W.W., et al., 2011. Ventilation rates and health: multidisciplinary review of the scientific literature. Indoor Air 21, 191-204.

Svanes, C., Heinrich, J., Jarvis, D., et al., 2003. Pet-keeping in childhood and adult asthma and hay fever: European community respiratory health survey. J. Allergy Clin. Immunol. 112, 289-300.

US Census Bureau, 2013. American housing survey for the United States: 2011 (current housing report, series H150/11). http://www.census.gov/content/dam/Census/ library/publications/2013/demo/h150-11.pdf (Access on: March 15, 2017).
US Census Bureau. (n.d.) Poverty thresholds. http://www.census.gov/cps/data/ povthresholds.html (Access on: March 15, 2017).

WHO European Centre for Environment and Health, 2005. Report on the WHO technical meeting on quantifying disease from inadequate housing. http://www.euro.who. int/_data/assets/pdf_file/0007/98674/EBD_Bonn_Report.pdf (Access on: March 15, 2017).

Zipf, G., Chiappa, M., Porter, K.S., et al., 2013. National health and nutrition examination survey: plan and operations, 1999-2010. Vital Health Stat. 1, 1-37. 